\title{
Hierarchy and the size of a firm
}

\section{Tobias Hiller $^{1}$ (D)}

Received: 23 October 2020 / Accepted: 26 March 2021 / Published online: 19 April 2021

(c) The Author(s) 2021

\begin{abstract}
In this note, we apply weighted hierarchical games of cooperative game theory to the problem of optimal firm size of the firm. In particular, we analyze the influence of production technology on the size of the firm. Our note enhances previous approaches using a permission structure with equally strong relationships between predecessor and direct successors.
\end{abstract}

Keywords Cooperative game theory $\cdot$ Hierarchy $\cdot \mathrm{wH}^{\mathrm{My}}$ value

JEL Classification C71 - L25

\section{Introduction}

In this paper, we apply the $\mathrm{wH}^{\mathrm{My}}$ value (weighted hierarchy value based on the Myerson value) introduced by Casajus et al. (2009) and Hiller (2014) to the problem of optimal size of the firm. Our approach is similar to the work done by van den Brink and Ruys (2008) using a value of cooperative game theory that takes hierarchies in firms into account. As in van den Brink and Ruys (2008), we analyze the influence of production technology on the size of the firm.

To analyze firms within the framework of cooperative game theory, it is necessary to model hierarchies within this framework. One approach was presented by Kalai and Samet (1987). They used ordered partitions and weights to model hierarchies. Winter (1989) used a sequence of bargaining components in the sense of Owen (1977) to model hierarchies. Both approaches model levels in the sense of Lazear and Rosen (1981), Carmichael (1983) and Prendergast (1993). Another approach involves antimatroid games (Algaba et al. 2003, 2004a, b). Unfortunately, these approaches are unable to model a manager-subordinate structure. For hierarchies in firms, this structure is a main characteristic (Radner 1992; Meagher 2001).

Tobias Hiller

hiller@wifa.uni-leipzig.de

1 Department of Microeconomics, University Leipzig, Leipzig, Germany 
Another approach in cooperative game theory that is used to model hierarchies applies an undirected graph/network on the set of players (Myerson 1977; Borm et al. 1992; Herings et al. 2008). However, the problem with this approach is that all players are symmetrical in the graph; there are no superiors and subordinates. In van den Brink (2008) a directed graph/permission structure on the set of players is used to analyze the effects of hierarchies on players' payoffs or to the wages of employees respectively. The basic idea of permission values is that a player/employee needs approval from all predecessors (Gilles et al. 1992; van den Brink and Gilles 1996). In van den Brink and Ruys (2008) the approach is used to determine the organizational structure of the firm by considering production technology.

In van den Brink (2008) single dominance relationships, i.e., the influence of a predecessor on direct successors, are equally strong. It is, however, a plausible assumption that the relations among the players may have different levels of strength (e.g., different leadership styles could be modelled by weights). Using this idea to enhance the modelling of hierarchies, Casajus et al. (2009) introduced the $\mathrm{wH}^{\mathrm{Sh}}$ value (a weighted hierarchy value based on the Shapley value). In this approach a weighted directed graph is used to model hierarchies. Two elements form the basis of the $\mathrm{wH}^{\mathrm{Sh}}$ value. First, in order to create the output, all players work symmetrically together. In this step, the output is distributed to the players according to the Shapley value (Shapley 1953). In a second step, the weighted hierarchy reallocates a certain fraction of these payoffs. The weighted hierarchy has only allocational effects. ${ }^{1}$ In Hiller (2014), the $\mathrm{wH}^{\mathrm{Sh}}$ value has been generalized for games with a cooperation structure/graph. ${ }^{2}$ This approach takes account of the coordinating role in the distribution of output; the players do not work symmetrically together (first step). The player who coordinates the remaining players will be rewarded if there is a cooperative win. Again, in the second step of calculating the payoffs, the weighted hierarchy reallocates a certain fraction of the payoffs that players obtain in the first step.

This paper applies the $\mathrm{wH}^{\mathrm{My}}$ value to analyze the question of optimal size of the firm. Our analysis is analogous to van den Brink and Ruys (2008). One result is that an increase of production technology increases the size of the firm. With respect to the theory of the firm, our approach could be a technical contribution. Other technical approaches with interesting insights for an optimal hierarchy are by Williamson (1967), Calvo and Wellisz (1978; 1979), Rosen (1982), Keren and Levhari (1979; 1989), Meagher and van Zandt (1998) and Meagher et al. (2003) for example.

The remainder of our article is organized as follows. In Sect. 2, we present some preliminaries. Section 3 provides results on the size of the firm. Section 4 concludes and outlines further research.

\footnotetext{
1 Some results on the wage structure of the firm and the allocation of employees in the firm if the $\mathrm{wH}^{\mathrm{Sh}}$ value is used as a wage scheme are deduced in Casajus et al. (2009). Since this paper is in German, the results are briefly presented in "Appendix 1".

2 One value for these games is the Myerson value My (Myerson 1977).
} 


\section{Preliminaries}

A transferable utility (TU) game is a pair $(N, v)$ where $N=\{1,2, \ldots, n\}$ is the non-empty and finite set of players. The number of players in $N$ is denoted by $n$ or $|N|$. The coalitional function $v$ assigns every subset $K \subseteq N$ a certain worth $v(K)$ reflecting the economic abilities of $K$, i.e., $v: 2^{N} \rightarrow \mathbb{R}$ and $v(\emptyset)=0$. A TU game $(N, v)$ is called symmetric if a function $f: N \rightarrow \mathbb{R}$ exists such that $v(K)=f(|K|)$ for all nonempty sets $K \subseteq N$. A symmetric game is monotone if $v(T)<v(S)$, for all $T \subset S, T, S \subseteq N$.

A value is an operator $\phi$ that assigns (unique) payoff vectors to all games $(N, v)$ (i.e., uniquely determines a payoff for every player in every TU game). One important value is the Shapley value. In order to calculate the players' payoffs, rank orders $\rho$ on $N$ are used. They are written as $\left(\rho_{1}, \ldots, \rho_{n}\right)$ where $\rho_{1}$ is the first player in the order, $\rho_{2}$ the second player, etc. The set of these orders is denoted by $R O(N) ; n !$ rank orders exist. The set of players before $i$ in rank order $\rho$ and player $i$ is called $K_{i}(\rho)$. The Shapley payoff of $i$ is the average of the marginal contributions taken over all rank orders (Shapley 1953):

$$
\operatorname{Sh}_{i}(N, v)=\frac{1}{n !} \sum_{\rho \in R O(N)} v\left(K_{i}(\rho)\right)-v\left(K_{i}(\rho) \backslash\{i\}\right) .
$$

Other value-like solution concepts of cooperative game theory are presented by Banzhaf (1965), Schmeidler (1969), Holler (1982) and Tijs (1987).

As in Gilles et al. (1992), van den Brink and Gilles (1996), van den Brink (1997), van den Brink (2008), van den Brink and Ruys (2008), Casajus et al. (2009) and van den Brink and Dietz (2014) the permission structure is a mapping $S: N \rightarrow 2^{N}$. To each player are assigned the players who are direct successors of $i$. $S$ can be interpreted as a directed graph (Bollobás 2002). $S(i)$ identifies the direct successors of $i$ with $i \notin S(i)$. $|S(i)|$ could be interpreted as span of control of player $i$. The players in $S^{-1}(i)=\{j \in N: i \in S(j)\}$ are the direct predecessors of $i ; S^{-1}(K)=\bigcup_{i \in K} S^{-1}(i)$.

For the hierarchy of the firm, we assume a tree structure as usual in the literature (Radner 1992; Meagher 2001). These structures satisfy two conditions:

- there is one player $i_{0} \in N$, such that $S^{-1}\left(i_{0}\right)=\emptyset$ and $\hat{S}\left(i_{0}\right)=N \backslash\left\{i_{0}\right\}$ and

- for every player $i \in N \backslash\left\{i_{0}\right\}$ we have $\left|S^{-1}(i)\right|=1$.

In a tree structure, a path $T$ in $N$ from $i$ to $j$ is a sequence of players $T(i, j)=\left\langle r_{0}, r_{1}, \ldots, r_{k-1}, r_{k}\right\rangle$ with $i=r_{0}, j=r_{k}$ and $r_{l+1} \in S\left(r_{l}\right)$ for all $l=0, \ldots, k-1$. A path can be interpreted as a chain of commands/chain of reporting between $i$ and $j$, whereby $i$ is a predecessor of $j$. The set of successors of $i$ is $\hat{S}(i):=\{j \in N \backslash\{i\}:$ there is a path from $i$ to $j\}$. Analogously, we denote the set of $i$ 's predecessors by $\hat{S}^{-1}(i):=\{j \in N \backslash\{i\}$ : there is a path from $j$ to $i\}$.

Besides the hierarchy $S$, weighted relationships between the players are taken into account. The vector $w: N \rightarrow \mathbb{R}$ assigns every player $i$ a weight $w_{i}, 0 \leq w_{i} \leq 1$. For $i_{0}$ we have $w_{i_{0}}=0$. If a vector maps all players the same weight $\bar{w}$, except $i_{0}$, i.e., $w_{i}=w_{j}=\bar{w}$ for all $i, j \in N \backslash\left\{i_{0}\right\}$, we denote the vector by $\bar{w}$. 
Hierarchy $S$ characterizes a level structure or partition $\mathfrak{Q}=\left(L_{0}, \ldots, L_{M}\right)$ of $N$ with

- $L_{0}=\left\{i_{0}\right\}$ and

- $L_{k}=\left\{i \in N \backslash \bigcup_{u=0}^{k-1} L_{u} \mid S^{-1}(i) \subset L_{k-1}\right\}, 1 \leq k \leq M, L_{M} \neq \emptyset$ and $L_{M+1}=\emptyset$.

The definition of the level structure characterizes a level by the distance to $i_{0}$ at the top of the firm, i.e., this can be called a top-down-hierarchy. ${ }^{3} L_{M}$ is the lowest level in the firm. We call players at the lowest level workers.

A weighted hierarchical game is a tuple $(N, v, S, w)$. A value for these games is an operator $\varphi$. The $\mathrm{wH}^{\mathrm{Sh}}$ value is one of these values. All players $j$, with $j \in \hat{S}^{-1}(g)$, respectively, and all players in the path $T\left(i_{0}, g\right)$, get a fraction of $g$ 's Shapley payoff. For $i \in N$ we calculate the fraction of $g^{\prime}$ s payoff by (Casajus et al. 2009):

$$
f_{i}(S, w, g)= \begin{cases}{\left[1-w_{i}\right]} & \prod_{\substack{l \in \hat{S}(i), l \in T\left(i_{0}, g\right)}} w_{l}, i \in T\left(i_{0}, g\right), \\ 0, & \text { else. }\end{cases}
$$

From this, we have for $\mathrm{wH}^{\text {Sh }}$ payoff of player $i \in N$ (Casajus et al. 2009):

$$
\mathrm{wH}_{i}^{\mathrm{Sh}}(N, v, S, w)=\sum_{j=1}^{n} f_{i}(S, w, j) \cdot \mathrm{Sh}_{j}(N, v) .
$$

For a literature review regarding values on games with hierarchies, see as an example van den Brink (2017).

In order to honor players who coordinate other players, the wH value based on the Myerson value (Myerson 1977) has been introduced and axiomatized (Hiller 2014). Some further preliminaries are necessary to introduce this value. First, a graph $L$ on the set of players is considered. The set of possible pairwise links between players is called $L^{N}=\{\{i, j\}: i, j \in N, i \neq j\}$, whereat $\{i, j\}$ and $\{j, i\}$, respectively, (or $i j$ and $j i)$ is the direct link between players $i$ and $j$. A cooperation structure $\mathrm{CO}$ on $N$ is a graph $(N, L)$ with $L \subseteq L^{N}$. A CO game is characterized by $(N, v, L)$. From hierarchy $S$ we construct $L_{S}$ in the following way: $L_{S}=\{i j: i \in S(j)\}$ for all $i, j \in N$; hence, the CO game $\left(N, v, L_{S}\right)$ results. The graph $L_{S}$. partitions $N$ into components $C_{1}, \ldots, C_{k}$. This partition is denoted by $N \backslash L_{S}$. Each player is in one component; $C_{i} \cap C_{j}=\emptyset, i \neq j, N=\bigcup C_{j} . N \backslash L_{S}(i)$ denotes the component of $i$. Two players $i$ and $j$ with $N \backslash L_{S}(i)=N \backslash L_{S}(j)$ are connected. The restricted coalitional function $\left.v\right|_{L_{S}}$ is given by:

$$
\left.v\right|_{L_{S}}(K):=\sum_{C \in K \backslash L_{S}} v(C) \forall K \subseteq N .
$$

\footnotetext{
3 The definition of the hierarchy is an adaption of the definition by Gilles et al. (1992).
} 
The worth of a coalition $K$ corresponds to the sum of the worths of its components. In the case $\left|K \backslash L_{S}\right|=1$ we have $v(K)=\left.v\right|_{L_{S}}(K)$. A CO value is an operator $\psi$ that assigns (unique) payoff vectors to all $\mathrm{CO}$ games. The most popular $\mathrm{CO}$ value is the Myerson value (Myerson 1977). According to this value, player $i^{\prime}$ s payoff is calculated by:

$$
\operatorname{My}_{i}\left(N, v, L_{S}\right)=\operatorname{Sh}_{i}\left(N,\left.v\right|_{L_{S}}\right)
$$

Further values for CO games are the position value (Borm et al. 1992), the average tree solution (Herings et al. 2008) and the center value (Navarro 2020). For a literature survey on CO games, see Slikker and van den Nouweland (2001) and Gilles (2010). With these preliminaries, $\mathrm{wH}_{i}^{\mathrm{My}}$ is calculated by (Hiller 2014):

$$
\mathrm{wH}_{i}^{\mathrm{My}}(N, v, S, w)=\sum_{j=1}^{n} f_{i}(S, w, j) \cdot \mathrm{My}_{j}\left(N, v, L_{S}\right)
$$

To exemplify the calculation, we introduce an example:

Example 1 For our example, we assume $N=\{1,2,3\}$ and

$$
v(K)=\left\{\begin{array}{cl}
2, & |K|=1 \\
10, & |K|=2 \\
15, & |K|=3 \\
0, & \text { else. }
\end{array}\right.
$$

In addition, we have $S(2)=S(3)=\varnothing, S(1)=\{2,3\}$, and $w=\left(0, \frac{1}{3}, \frac{1}{4}\right)$. For $\left.v\right|_{L_{S}}$, we have:

$$
\left.v\right|_{L_{S}}(K)= \begin{cases}2, & |K|=1 \\ 4, & K=\{2,3\} \\ 10, & K=\{1,2\}, K=\{1,3\} \\ 15, & |K|=3 \\ 0, & \text { else. }\end{cases}
$$

From these assumptions, we obtain $\operatorname{My}_{2}\left(N, v, L_{S}\right)=\operatorname{My}_{3}\left(N, v, L_{S}\right)=4$ and $\operatorname{My}_{1}\left(N, v, L_{S}\right)=7$. Since player 1 coordinates the other players, player 1 gets a higher payoff. For the $\mathrm{wH}^{\mathrm{My}}$ payoffs, we have:

$$
\mathrm{wH}_{1}^{\mathrm{My}}(N, v, S, w)=9 \frac{1}{3}, \mathrm{wH}_{2}^{\mathrm{My}}(N, v, S, w)=2 \frac{2}{3}, \mathrm{wH}_{3}^{\mathrm{My}}(N, v, S, w)=3 .
$$

Building on our definition of a weighted hierarchical game $(N, v, S, w)$ and the calculation of $\mathrm{wH}_{i}^{\mathrm{My}}(N, v, S, w)$ we can sketch the roles of various players in the firm. In our analysis in Sect. 3, only the workers at $L_{M}$ are productive with respect to $v$. Managers in the levels between $L_{M}$ and $i_{0}$ generate an additional worth, if cooperation between workers is superadditive. Analogous to van den Brink and Ruys (2008), we interpret $i_{0}$ as an owner of the firm, i.e., the payoff of $i_{0}$ is the profit of 
the firm. Hence, the structure and size of the firm that maximizes $i_{0}$ 's payoff is profit maximizing (see Sect. 3). The weights $w_{i}$ can be interpreted as the level of redistribution/exploitation in the firm. High weights result in a large part of the worth being redistributed to $i_{0}$. If the worth is not only interpreted in monetary terms, this could also be mean that superiors like to bask in the success of their employees-and thus as part of the corporate culture. Outside our model, this can lead to a low incentive for innovation or performance when there is hidden information. Like the span of control $|S(i)|$, the weights $w_{i}$ as well as the coalition function $v$ are given exogenous.

\section{Results}

In this section, we present some new insights regarding the structure and size of the firm based on the $\mathrm{wH}^{\mathrm{My}}$ value as a scheme that allocates produced worth to the players. For the structure and production technology of the firm, we assume (again analogous to van den Brink and Ruys (2008)):

- $w_{i}=w, 0<w<1$, for all $i \in N \backslash\left\{i_{0}\right\}$,

- $|S(i)|=s \geq 1$ for all $i \in N \backslash L_{M}$, and

- $v:\left\{1, \cdots,\left|L_{M}\right|\right\} \rightarrow \mathbb{R}^{+}$.

For our firm, we have a constant weight $\bar{w}$ for all employees without $i_{0}$ at the top of the firm. The span of control $s$ is equal in the whole firm. So in an m-level firm, the number of employees (with $i_{0}$ ) equals $n=\sum_{k=0}^{m} s^{k}=\frac{s^{m+1}-1}{s-1}$. The number of workers at the lowest level is given by $\left|L_{M}\right|=s^{m}$. Only these workers influence the coalitional function $v(K)$. In addition, the workers are identical with respect to $v(K)$. In van den Brink and Ruys (2008), the coordination costs per level are a percentage $\alpha, 0<\alpha<1$. They have the effect that adding a level (increasing the firm size) may thus benefit $i_{0}$ by increasing the scale of production, at the cost of an increase in coordination costs (Williamson 1967). In our model, $w$ can be interpreted as level costs, since the employees between the workers and $i_{0}$ acquire a part of the worth produced by workers.

Example 2 A firm with $N=\{1,2,3\}, S(2)=S(3)=\varnothing, S(1)=\{2,3\}, \quad$ and $w=\frac{1}{3} \forall i \in N \backslash\{1\}$ meets the requirements. The span of control is 2 .

For first insights, we assume a linear relation between the number of workers and the worth produced; i.e., there is a production function $p$ based on the set of workers $L_{M}$ with $p: L_{M} \rightarrow \mathbb{R}, p(K)=c \cdot|K|$, for all nonempty sets $K \subseteq L_{M}$ with $c>0$. From this we deduce the coalitional function $v$ with:

$$
v(K)= \begin{cases}c \cdot\left|L_{M} \cap K\right|, & L_{M} \cap K \neq \emptyset \\ 0, & \text { else. }\end{cases}
$$

The worth produced by the firm is $v(N)=c \cdot s^{m}$. Applying the $\mathrm{wH}^{\mathrm{My}}$ value, we have in a first step for the Myerson payoffs: 
Fig. 1 Example: Firm B

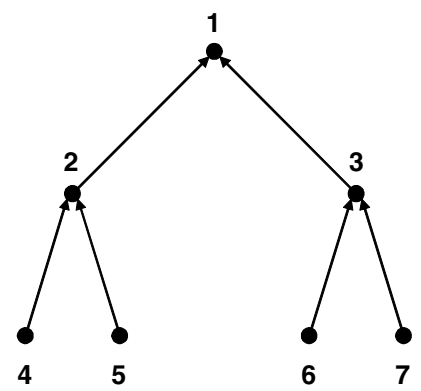

$$
\operatorname{My}_{i}\left(N, v, L_{S}\right)=c, i \in L_{M} \text { and } \operatorname{My}_{j}\left(N, v, L_{S}\right)=0, j \in N \backslash L_{M} .
$$

Based on these payoffs, the following $\mathrm{wH}^{\mathrm{My}}$ payoffs occur:

$$
\begin{array}{r}
\mathrm{wH}_{i}^{\mathrm{My}}(N, v, S, w)=\left(1-w_{i}\right) \cdot c, \\
i \in L_{M} \mathrm{wH}_{i_{0}}^{\mathrm{My}}(N, v, S, w)=s^{m} \cdot w^{m} \cdot c .
\end{array}
$$

Since the production function $p$ is linear in $\left|L_{M}\right|$, the coordination by $i_{0}$ does not generate marginal contributions. From this, we deduce our first result regarding the size of the firm: ${ }^{4}$

Theorem 3 In a firm with a linear production function $p$ and an allocation of the worth using the $\mathrm{wH}^{\mathrm{My}}$ value, there is no optimal size from the point of view of $i_{0}$.

The proof is given in "Appendix 2". Hence, there is no optimal size of the firm. If $s \cdot w>1, i_{0}$ could increase the payoff by adding an additional level to the firm. Hence, without more detailed modelling, the constellation of $s, w$ and $c$ provides only an initial indication of whether the firm exists or not. A short example illustrates this:

Example 4 The firm of Example 2 is the starting point and called firm $A$. In addition, the production function for the workers is given by $p_{A}(K)=2 \cdot|K|, K \subseteq L_{M}$. For the payoffs, we have $\mathrm{My}_{1}\left(N_{A}, v_{A}, L_{S_{A}}\right)=0, \mathrm{My}_{2}\left(N_{A}, v_{A}, L_{S_{A}}\right)=\operatorname{My}_{3}\left(N_{A}, v_{A}, L_{S_{A}}\right)=2$ and $\mathrm{wH}_{i}^{\mathrm{My}}\left(N_{A}, v_{A}, S_{A}, w_{A}\right)=\frac{4}{3} \forall i \in N$. With respect to Theorem 3 , we have case $s \cdot w<1$. Adding a new level gives a firm $B$ with $N_{B}=\{1, \ldots, 7\}, S_{B}(j)=\varnothing$ with $j \in\{4,5,6,7\}, S_{B}(2)=\{4,5\}, S_{B}(3)=\{6,7\}, S_{B}(1)=\{2,3\}$ and $w_{B}=\frac{1}{3} \forall i \in N \backslash\{1\}$; see Fig. 1 . The Myerson payoffs for the players in the last level are unchanged. For $\mathrm{wH}^{\mathrm{My}}$ payoffs, we obtain $\mathrm{wH}_{i}^{\mathrm{My}}\left(N_{B}, v_{B}, S_{B}, w_{B}\right)=\frac{4}{3} \forall i \in L_{M}, \mathrm{wH}_{j}^{\mathrm{My}}\left(N_{B}, v_{B}, S_{B}, w_{B}\right)=\frac{8}{9} \forall j \in L_{M-1} \quad$ and $\mathrm{wH}_{i_{0}}^{\mathrm{My}}\left(N_{B}, v_{B}, S_{B}, w_{B}\right)=\frac{8}{9}$; the payoff for $i_{0}$ has been reduced.

\footnotetext{
${ }^{4}$ We assume that $s$ is given exogenous. Without this assumtion, $i_{0}$ would prefer a raise in $s$ to a raise in $m$.
} 
Table 1 Productivity and firm size

\begin{tabular}{llllll}
\hline \multicolumn{5}{c}{$m=2$} \\
\hline & $m=1$ & & & \\
$w=0$ & $\mathrm{wH}_{i_{0}}^{\mathrm{My}}$ & $\mathrm{wH}_{j}^{\mathrm{My}}$ & $\mathrm{wH}_{i_{0}}^{\mathrm{My}}$ & $\mathrm{wH}_{l}^{\mathrm{My}}$ & $\mathrm{wH}_{j}^{\mathrm{My}}$ \\
$w=0.1$ & 0.1261 & 1.1261 & 0.1973 & 0.3234 & 1.2032 \\
$w=0.2$ & 0.5766 & 1.0135 & 0.3101 & 0.5076 & 1.0829 \\
$w=0.3$ & 0.8018 & 0.7883 & 0.5191 & 0.6437 & 0.9626 \\
$w=0.4$ & 1.0270 & 0.6757 & 1.2260 & 0.7317 & 0.8422 \\
$w=0.5$ & 1.2523 & 0.5631 & 1.7239 & 0.7633 & 0.7219 \\
$w=0.6$ & 1.4775 & 0.4505 & 2.3180 & 0.7069 & 0.4813 \\
$w=0.7$ & 1.7027 & 0.3378 & 3.0083 & 0.6024 & 0.3610 \\
$w=0.8$ & 1.9279 & 0.2252 & 3.7949 & 0.4497 & 0.2406 \\
$w=0.9$ & 2.1532 & 0.1126 & 4.6778 & 0.2489 & 0.1203 \\
\hline
\end{tabular}

In the next step, we assume a production function on the set of workers $L_{M}$ with $p(K)=|K|^{\gamma}, K \subseteq L_{M}$ with $\gamma>0$. If $\gamma>1$, coordinating the workers generates an additional worth. The exponent $\gamma$ could be interpreted as technology of the firm. A higher $\gamma$ means higher productivity by the workers. Applying the $\mathrm{wH}^{\mathrm{My}}$ value results in an optimization process. In a general analysis we get:

Theorem 5 In a firm with a production function $p$ with $0<\gamma \leq 1$ and an allocation of the worth using the $\mathrm{wH}^{\mathrm{My}}$ value there is an optimal size of the firm, i.e., there is a $\widehat{m}$ with $\mathrm{wH}_{i_{0}}^{\mathrm{My}}(\hat{N}, v, S, w) \geq \mathrm{wH}_{i_{0}}^{\mathrm{My}}(\bar{N}, v, S, w)$ with $|\widehat{N}|=\sum_{k=0}^{\hat{m}} s^{k}$ and $|\bar{N}|=\sum_{k=0}^{\bar{m}+1} s^{k}$.

The proof is given in "Appendix 2". It is also possible in firms with $\gamma>1$ that an optimization process may occur. To illustrate this, we present an example with $p(K)=|K|^{\frac{3}{4}}$ and $s=2$. Table 1 shows the results for $i_{0}, j \in L_{M}$ and $l \in N \backslash\left\{\left\{i_{0}\right\} \cup L_{M}\right\}$. In the case of $w=0.1$, it is not worth it for $i_{0}$ to insert an additional level of employees in the firm with an aim to raise the number of workers.

In addition, we deduce from Eqs. 6 and 11:

Corollary 6 In a firm with a production function $p$ with $0<\gamma$ an increase in

- span of control s

- weightw

- productivity of workers $\gamma$

increases the (optimal) size of the firm. 
Hence, the higher the productivity of the workers, the larger a firm will be. The same holds for the span of control and the allocation weight.

Analogous to van den Brink and Ruys (2008), finally we briefly consider a reservation wage for workers in $L_{M}{ }^{5}$ This wage is denoted by $r_{i}$ for $i \in L_{M}$ with $r_{i} \in \mathbb{R}^{+}$. For workers in $L_{M}$ this wage is the lowest wage rate at which they are willing to work at the firm. Hence, $\mathrm{wH}_{i}^{\mathrm{My}}(N, v, S, w) \geq r_{i}$ is necessary. For firms that are exposed with an optimization process as noted in Theorem 5 or Table 1, an increase of reservation wages/minimum wages could reduce the optimal number of levels. This occurs if the new reservation wage is above the worker's wage $\mathrm{wH}_{i}^{\mathrm{My}}(N, v, S, w)$. In order for the worker to continue to operate at the firm, the weight $w$ must be lowered. This reduces the optimal number of levels $\hat{m}$. Hence, the payoff for $i_{0}$ is bounded above by the reservation wage. This result is in line with van den Brink and Ruys (2008).

\section{Conclusion}

In this note, we apply the $\mathrm{wH}^{\mathrm{My}}$ value to determine the optimal size of the firm from the point of view of the owner $i_{0}$ of the firm. In modelling with a linear production function $p(K)=c \cdot|K|$, an increase of level costs/weights $w$ and an increase in the span of control $s$, increases the probability that the firm exists. For production function $p(K)=|K|^{\gamma}$ the higher productivity of workers at the lowest level of the firm leads to an increase in optimal firm size. In addition, an increase of $w$ and an increase of $s$ are combined with a growing optimal size of the firm. This intuitive result shows that the $\mathrm{wH}^{\mathrm{My}}$ value is an appropriate method to model the allocation of the produced worth in the firm.

With respect to other technical approaches mentioned in the Introduction, in Williamson (1967), two factors limit the size of the firm/span of control. On the one hand, the quality of the information that the manager receives at the top position of the firm decreases, since each additional hierarchical level has a negative impact on this quality. In addition, the quantity of information to be processed by the top manager increases with the size of the company, so this is also a limiting factor. This modeling was enhanced by Calvo and Wellisz (1978; 1979). Their analysis assumes asymmetric information regarding the effort of employees at lower levels/ hidden action of these employees. The limitation of firm size is caused by loss of control and the high costs of supervision. In our model, asymmetric information is not considered. In addition, Calvo and Wellisz (1978; 1979) show that reservation wages/minimum wages could increase employment since higher wages reduce workers' incentive to shirk and therefore reduces the required supervision and additional employees can be hired and observed. In our model, an increase in the minimum wage cannot lead to an increase in the size of the firm. In Rosen (1982), the

\footnotetext{
${ }^{5}$ For a detailed analysis, the coalition structure approach of cooperative game theory should be used to model the refusal of workers. In addition, a non-cooperative game with a sequence of player decisions is necessary.
} 
hierarchy and size of the firm is an outcome of assignments of employees to hierarchical positions. More able employees are allocated to top positions and firms with persons of superior talent in top positions are larger. In our analysis, workers in the last level are symmetric and so we do not capture this question (see "Appendix 1" for results from Casajus et al. (2009)). In Keren and Levhar (1979; 1989) the span of control for every firm level is a result of minimizing labor costs on the one hand and costs caused by delays in decision making on the other. One result is that the span of control is higher at lower hierarchy levels. In our model, the span of control is exogenous and the optimization remains open for further research. In Meagher and van Zandt (1998) and Meagher et al. (2003), information processing is the production activity of firms. Hierarchies/firms with more than one employee occurs in order to accelerate/parallelize information processing. The wages of employees and the cost of delay in information processing determine the optimal size of the firm. With respect to our model, the coalition function can be interpreted as the speed of information processing. The managers of the firm coordinate this processing. Adding more managers/hierarchy levels increases the number of information processing workers at the lowest hierarchy level-but delays increase due to additional coordination.

For a linear case, our results are in line with van den Brink and Ruys (2008). In their article, the owner chooses the deepest organization if a certain amount for $w$ (in their article $\alpha$ ) is exceeded. For a Cobb-Douglas production function, their approach gives: if there exists an optimal number of levels, the number of levels is one. We think that our approach is more intuitive at this point.

On a more abstract level on the theory of the firm, our technical contribution-in particular $w$-may be used to model the efficiency of the management of the firm in the context of "transaction cost" theories (Coase 1937; Williamson 1975, 1985). The property rights approach of the theory of the firm (Grossman and Hart 1986; Hart and Moore 1990) has strong similarity with concepts of cooperative game theory. Hence, the integration of hierarchical structures of cooperative game theory seems to be possible. For the third line of the theory of the firm-the contracting approach-or the principal-agent approach, respectively-(Alchian and Demsetz 1972; Jensen and Meckling 1976) the player's payoffs in the cooperative game could be used as possible outcomes in a principal-agent game.

In our modeling, $w_{i}, s$ and $v$ are exogenous. This can also be enhanced in future research. For example, it is conceivable that $i_{0}$ has a choice between investing in production technology (and hence $v$ ) or investing in organizational innovation (an increase in $s$ ).

In addition, our approach and the other values by cooperative game theory mentioned in the introduction could be used to analyze the question of to whom the profits of a firm belong - capital, labor or the entrepreneur. In our model of the firm's hierarchy, $i_{0}$ is the owner (capital, entrepreneur) of the firm. ${ }^{6}$ To model multiple shareholders of the firm instead of only one player $i_{0}$, weighted voting games could

\footnotetext{
${ }^{6}$ Starting with Berle and Means (1932), there is a large amount of literature on the separation of ownership and control of the firm.
} 
be used (Shapley and Shubik 1954). Level $L_{0}$ could be a component in the sense of Owen (1977) (or Winter 1989 respectively), with the shareholders as members of this component. ${ }^{7}$ A further enhancement could be a modification of the production function of the firm with aspects of an apex game (von Neumann and Morgenstern 1944). An overview of the existing literature on apex games is provided by Montero (2002). To model social development between capital providers, entrepreneurs and workers over time, dynamic/evolutionary cooperative game theory (see Newton (2018) for an overview and Casajus et al. (2020) for some new insights) could be applied.

Additionally, our approach provides at least two starting points for future theoretical research. First, the coalition structure approach of cooperative game theory (Aumann and Drèze 1974) can be used to model the possibility of $i_{0}$ to split up the firm into several companies. Hence, this provides an opportunity to analyze not only the number of hierarchical levels, but also the number of firms. In addition, other $\mathrm{CO}$ values can be used as a basis for the $\mathrm{wH}$ value to analyze the robustness of our insights.

Another line for future research could be amalgamating the hierarchical approach of cooperative game theory as used in our article and the research done by Newton et al. (2019). In their article, employees of a team have ties to employees of other teams; and as such, there is an additional communication network in the firm besides the disciplinary hierarchy in our model.

\section{Appendix 1}

\section{Remuneration}

First, Casajus et al. (2009) presented results for special cases of employees:

Definition 7 An employee $i$ is called inessential, if $v(K)=v(K \backslash\{j\})$ with $j \in \hat{S}(i) \cup\{i\}$ for all $K \subseteq N$.

Hence, $i$ and all direct and indirect subordinates contribute zero to all coalitions.

Corollary 8 For an inessential employee $i$, we have $\mathrm{wH}_{i}^{\mathrm{Sh}}(N, v, S, w)=0$.

Definition 9 An employee $i$ is called unproductive and without influence, if $v(K)=v(K \backslash\{i\})$ for all $K \subseteq N$ and $w_{j}=0$ for all $j \in S(i)$.

Corollary 10 For an unproductive employee $i$ without influence, we have $\mathrm{wH}_{i}^{\mathrm{Sh}}(N, v, S, w)=0$.

\footnotetext{
7 A starting point for analyzing voting power distribution in stock corporations with cooperative game theory is Leech (1988).
} 
Definition 11 An employee $i$ is called unproductive and without subordinates, if $v(K)=v(K \backslash\{i\})$ for all $K \subseteq N$ and $S(i)=\emptyset$.

Corollary 12 For an unproductive employee $i$ without subordinates, we have $\mathrm{wH}_{i}^{\mathrm{Sh}}(N, v, S, w)=0$.

In addition, there are results for the wage structure of the firm.

Theorem 13 If the firm has an uniform weight $w_{i}=\bar{w}, 0<\bar{w}<1$, for all $i \in N \backslash\left\{i_{0}\right\}$ and all employees have a positive Shapley payoff, $\operatorname{Sh}_{i}(N, v)>0$ there is a $\bar{w}$ such that for all $i, j \in N$ with $j \in S(i)$ we have $\mathrm{wH}_{j}^{\mathrm{Sh}}(N, v, S, \bar{w})<\mathrm{wH}_{i}^{\mathrm{Sh}}(N, v, S, \bar{w})$.

Definition 14 A firm is called symmetric, if

- $\operatorname{Sh}_{i}(N, v)=: \overline{\operatorname{Sh}}(N, v)$ for all $i \in N$,

- $w_{i}=\bar{w}, 0<\bar{w}<1$, for all $i \in N \backslash\left\{i_{0}\right\}$ and

- $|S(i)|=s \geq 1$ for all $i \in N \backslash L_{M}$.

Hence, the span of control is equal for all levels $L_{0}$ to $L_{M-1}$.

Theorem 15 In a symmetric firm with a monotone coalition function $v$ and $v(N)>0$ we have $\mathrm{wH}_{i}^{\mathrm{Sh}}(N, v, S, w) \geq \mathrm{wH}_{j}^{\mathrm{Sh}}(N, v, S, w)$ for all $i \in L_{k}, j \in L_{k+1}, 0 \leq k \leq M-1$.

\section{Allocation}

In addition, Casajus et al. (2009) obtained results for the allocation of employees in the firm. For these results, the authors introduce an abstract hierarchy of the firm representing the positions. The set of positions is denoted by $P$. The function $T$ with $T: P \rightarrow 2^{P}$ describes the graph on the set of positions (analogous to $S$ ). The function $T$ fulfills the same properties as the function $S$. The position on top of the firm is $o$. Hence, we have $\left|T^{-1}(x)\right|=1$ for all $x \in P \backslash\{o\}$. The vector with the positions' weights is called $m$ with $m: P \rightarrow[0,1]$ and $m_{o}=0$. Hence, the position $o$ on top of the firm has a weight 0 .

Definition 16 An abstract hierarchical structure is characterized by $(P, T, m)$.

In addition to the abstract hierarchical structure there is a cooperative game $(N, v)$. The connection between $(P, T, m)$ and $(N, v)$ is done by an allocation function $\beta$. This bijective function allocates every employee to a position, $\beta: N \rightarrow P$. The set of allocations is called $B(T, N)$. Every $\beta$ generates a hierarchy $S^{\beta}$ and a weight vector $w^{\beta}$. For the set of direct subordinates of $i \in N$ with respect to $\beta$ we have $S^{\beta}(i):=\beta^{-1}(T(\beta(i)))$. The position of $i$ is denoted by $\beta(i)$. The set of positions that are directly subordinate to position $\beta(i)$ are $T(\beta(i))$. Hence, with $\beta^{-1}(T(\beta(i)))$ the set of employees on subordinate positions is addressed. Analogously, it is possible to determine indirect subordinates and direct and indirect superiors of $i$. The weight of $i \in N$ is determined by $w_{i}^{\beta}:=m(\beta(i))$. 
Definition 17 The function $T$ characterizes a partition or level structure $\mathfrak{Q}^{P}=\left(L_{0}^{P}, \ldots, L_{M}^{P}\right)$ of positions $P$ with

- $\quad L_{0}^{P}=\{o\}$ and

- $L_{k}^{P}=\left\{x \in P \backslash \bigcup_{u=0}^{k-1} L_{u}^{P} \mid T^{-1}(x) \subset L_{k-1}^{P}\right\}, 1 \leq k \leq M, L_{M}^{P} \neq \emptyset$ and $L_{M+1}^{P}=\emptyset$.

For the level of player $i$, we have $L_{k}^{\beta}:=\beta^{-1}\left(L_{k}^{P}\right)$.

Definition 18 An abstract hierarchical structure is called symmetric with respect to the weights if $m_{x}=: m_{L_{k}^{P}}$ if for all $x \in L_{k}^{P}$, with $k=0, \ldots, M$.

The definition of an abstract symmetric hierarchy is weaker than the definition of a symmetric firm that requires in addition symmetric Shapley payoffs, weights $\bar{w}$ and span of control.

Theorem 19 Given a firm with an abstract hierarchical structure with respect to the weights, $(P, T, m)$, with $0<m_{x}<1$ for all $x \in P \backslash\{o\}$, and the tupel $(N, v)$, with $|N|=|P|$. Employee $i_{0}$ is already allocated to position $o, \beta^{-1}(o)=i_{0}$ and decides on the further structuring of $\beta$. Employee $i_{o}$ aims to maximize payoff with $\beta_{\mathrm{opt}}$ :

$$
\beta_{\mathrm{opt}} \in \underset{\beta \in B(T, N), \beta(o)=i_{0}}{\arg \max } \mathrm{wH}_{i_{0}}^{\mathrm{Sh}}\left(N, v, w^{\beta}, S^{\beta}\right) .
$$

Employee $i_{0}$ allocates the other employees to positions such that we have from $i \in L_{k}^{\beta}$ and $j \in L_{l}^{\beta}$, with $1 \leq k \leq l \leq M, \operatorname{Sh}_{i}(N, v) \geq \operatorname{Sh}_{j}(N, v)$.

Hence, $i_{0}$ allocates the most productive employees to positions at the next level next.

Corollary 20 After the allocation of employees done by $i_{0}$, no other employee from $N \backslash\left\{i_{0}\right\}$ has an incentive to change the allocation in the subtree from their position.

The result is in line with Calvo and Wellisz (1979), Rosen (1982), Waldman (1984) and Qian (1994) and provides an argument as to why more able employees are at higher levels of a firm.

\section{Appendix 2}

\section{Proof of Theorem 3}

We have 


$$
\frac{\partial\left((s w)^{m} \cdot c\right)}{\partial m}=\underbrace{(s \cdot w)^{m} c}_{>0}(\ln s \cdot w) .
$$

If $s \cdot w>1$, we have $(\ln s \cdot w)>0$, i.e., a positive effect of increasing the number of levels.

\section{Proof of Theorem 5}

For production function $p(K)=|K|^{\gamma}, K \subseteq L_{M}$, we have $\lim _{K \rightarrow \infty} \frac{d^{2} p^{\prime \prime}(K)}{d K^{2}}=0$. Hence, in case $w=1$ ( $i_{0}$ obtains the whole worth produced) the optimal number of levels would be $\hat{m}=\infty$. A weight $w<1$ lowers the $\mathrm{wH}^{\mathrm{My}}$ payoff of $i_{0}$ and hence, the optimal number of levels is reduced.

Acknowledgement I am grateful to an anonymous referee for helpful comments on this paper.

Funding Open Access funding enabled and organized by Projekt DEAL. No funds, grants, or other support was received.

\section{Declaration}

Conflict of interest The authors declare that they have no conflict of interest.

Open Access This article is licensed under a Creative Commons Attribution 4.0 International License, which permits use, sharing, adaptation, distribution and reproduction in any medium or format, as long as you give appropriate credit to the original author(s) and the source, provide a link to the Creative Commons licence, and indicate if changes were made. The images or other third party material in this article are included in the article's Creative Commons licence, unless indicated otherwise in a credit line to the material. If material is not included in the article's Creative Commons licence and your intended use is not permitted by statutory regulation or exceeds the permitted use, you will need to obtain permission directly from the copyright holder. To view a copy of this licence, visit http://creativecommons.org/licen ses/by/4.0/.

\section{References}

Alchian AA, Demsetz H (1972) Production, information costs, and economic organization. Am Econ Rev 62(5):777-795

Algaba E, Bilbao JM, van den Brink R, Jiménez-Losada A (2003) Axiomatizations of the Shapley value for cooperative games on antimatroids. Math Methods Oper Res 57:49-65

Algaba E, Bilbao JM, van den Brink R, Jiménez-Losada A (2004a) An axiomatization of the Banzhaf value for cooperative games on antimatroids. Math Methods Oper Res 59:147-166

Algaba E, Bilbao JM, van den Brink R, Jiménez-Losada A (2004b) Cooperative games on antimatroids. Discrete Math 282(1-3):1-15

Aumann RJ, Drèze JH (1974) Cooperative games with coalition structures. Int J Game Theory 3(4):217-237

Banzhaf JF (1965) Weighted voting doesn't work: a mathematical analysis. Rutgers Law Rev $19(2): 317-343$

Berle AA, Means GC (1932) The modern corporation and private property. Harcourt, Brace \& World, New York 
Bollobás B (2002) Modern graph theory, 3rd edn. Springer, New York

Borm P, Owen G, Tijs S (1992) On the position value for communication situations. SIAM J Discrete Math 5(3):305-320

Calvo GA, Wellisz S (1978) Supervision, loss of control, and the optimum size of the firm. J Polit Econ 86(5):943-952

Calvo GA, Wellisz S (1979) Hierarchy, ability, and income distribution. J Polit Econ 87(5):991-1010

Carmichael L (1983) Firm-specific human capital and promotion ladders. Bell J Econ 14(1):251-258

Casajus A, Hiller T, Wiese H (2009) Hierarchie und Entlohnung. Zeitschrift für Betriebswirtschaft 79(7/8):929-954

Casajus A, Kramm M, Wiese H (2020) Asymptotic stability in the Lovász-Shapley replicator dynamic for cooperative games. J Econ Theory 186(1):104993

Coase RH (1937) The nature of the firm. Economica 4(16):386-405

Gilles RP (2010) The cooperative game theory of networks and hierarchies. Springer, Berlin

Gilles RP, Owen G, van den Brink R (1992) Games with permission structures: the conjunctive approach. Int J Game Theory 20(3):277-293

Grossman SJ, Hart OD (1986) The costs and benefits of ownership: a theory of vertical and lateral integration. J Polit Econ 94(4):691-719

Hart OD, Moore J (1990) Property rights and the nature of the firm. J Polit Econ 98(6):1119-1158

Herings PJJ, van der Laan G, Talman D (2008) The average tree solution for cycle-free graph games. Games Econ Behav 62(1):77-92

Hiller T (2014) The generalized wh value. Theor Econ Lett 4(3):247-253

Holler MJ (1982) Forming coalitions and measuring voting power. Polit Stud 30(2):262-271

Jensen MC, Meckling WH (1976) Theory of the firm: managerial behavior, agency costs and ownership structure. J Financ Econ 3(4):305-360

Kalai E, Samet D (1987) On weighted Shapley values. Int J Game Theory 16(3):205-222

Keren M, Levhari D (1979) The optimum span of control in a pure hierarchy. Manag Sci 25(11):1162-1172

Keren M, Levhari D (1989) Decentralization, aggregation, control loss and costs in a hierarchical model of the firm. J Econ Behav Organ 11(2):213-236

Lazear EP, Rosen S (1981) Rank-order tournaments as optimum labor contracts. J Polit Econ 89(5):841-864

Leech D (1988) The relationship between shareholding concentration and shareholder voting power in British companies: a study of the application of power indices for simple games. Manag Sci 34(4):509-527

Meagher KJ (2001) The impact of hierarchies on wages. J Econ Behav Organ 45(4):441-458

Meagher K, van Zandt T (1998) Managerial costs for one-shot decentralized information processing. Rev Econ Des 3(4):329-345

Meagher K, Orbay H, Van Zandt T (2003) Hierarchy size and environmental uncertainty. In: Sertel MR, Koray S (eds) Advances in economic design. Springer, Berlin, pp 439-457

Montero M (2002) Non-cooperative bargaining in apex games and the kernel. Games Econ Behav 41(2):309-321

Myerson RB (1977) Graphs and cooperation in games. Math Oper Res 2(3):225-229

Navarro F (2020) The center value: a sharing rule for cooperative games on acyclic graphs. Math Soc Sci 105:1-13

Newton J (2018) Evolutionary game theory: a renaissance. Games 9(2):31

Newton J, Wait A, Angus DS (2019) Watercooler chat, organizational structure and corporate culture. Games Econ Behav 118(1):354-365

Owen G (1977) Values of games with a priori unions. In: Henn R, Moeschlin O (eds) Essays in mathematical economics \& game theory. Springer, Berlin, pp 76-88

Prendergast C (1993) The role of promotion in inducing specific human capital acquisition. Q J Econ 108(2):523-534

Qian Y (1994) Incentives and loss of control in an optimal hierarchy. Rev Econ Stud 61(3):527-544

Radner R (1992) Hierarchy: the economics of managing. J Econ Lit 30(3):1382-1415

Rosen S (1982) Authority, control, and the distribution of earnings. Bell J Econ 13(2):311-323

Schmeidler D (1969) The nucleolus of a characteristic function game. SIAM J Appl Math 17(6): $1163-1170$

Shapley LS (1953) A value for n-person games. In: Kuhn HW, Tucker AW (eds) Contributions to the theory of games, vol 2. Princeton University Press, Princeton, pp 307-317 
Shapley LS, Shubik M (1954) A method for evaluating the distribution of power in a committee system. Am Polit Sci Rev 48(3):787-792

Slikker M, van den Nouweland A (2001) Social and economic networks in cooperative game theory. Kluwer, Boston

Tijs SH (1987) An axiomatization of the t-value. Math Soc Sci 13(2):177-181

van den Brink R (1997) An axiomatization of the disjunctive permission value for games with a permission structure. Int J Game Theory 26(1):27-43

van den Brink R (2008) Vertical wage differences in hierarchically structured firms. Soc Choice Welf 30(2):225-243

van den Brink R (2017) Games with a permission structure-a survey on generalizations and applications. TOP 25:1-33

van den Brink R, Dietz C (2014) Games with a local permission structure: separation of authority and value generation. Theory Decis 76:343-361

van den Brink R, Gilles RP (1996) Axiomatizations of the conjunctive permission value for games with permission structure. Games Econ Behav 12(1):113-126

van den Brink R, Ruys PHM (2008) Technology driven organizational structure of the firm. Ann Finance 4:481-503

von Neumann J, Morgenstern O (1944) Theory of games and economic behavior. Princeton University Press, Princeton

Waldman M (1984) Worker allocation, hierarchies and the wage distribution. Rev Econ Stud 51(1):95-109

Williamson OE (1967) Hierarchical control and optimum firm size. J Polit Econ 75(2):123-138

Williamson OE (1975) Market and hierarchies: analysis and antitrust implications. The Free Press, New York

Williamson OE (1985) The economic institutions of capitalism: firms, markets, relational contracting. Free Press, New York

Winter E (1989) A value for cooperative games with levels structure of cooperation. Int J Game Theory $18(2): 227-240$

Publisher's Note Springer Nature remains neutral with regard to jurisdictional claims in published maps and institutional affiliations. 